\section{(6) OPEN ACCESS}

\title{
Engaging young adult clients of community pharmacies for HIV screening in Coastal Kenya: a cross-sectional study
}

\author{
Peter M Mugo, ${ }^{1}$ Henrieke A B Prins, ${ }^{1}$ Elizabeth W Wahome, ${ }^{1}$ Grace M Mwashigadi, ${ }^{1}$ \\ Alexander N Thiong'o, ${ }^{1}$ Evanson Gichuru, ${ }^{1}$ Anisa Omar, ${ }^{2}$ Susan M Graham, ${ }^{1,3}$ \\ Eduard J Sanders ${ }^{1,4,5}$
}

${ }^{1}$ Kenya Medical Research Institute, Kilifi, Kenya ${ }^{2}$ Ministry of Health, Kilifi, Kenya

${ }^{3}$ University of Washington, Seattle, USA

${ }^{4}$ Oxford University, Headington, UK

${ }^{5}$ University of Amsterdam, Amsterdam, The Netherlands

\section{Correspondence to} Dr Peter Mwangi Mugo, KEMRI-Wellcome Trust Research Programme, PO BOX 230, Kilifi 80108, Kenya; PMugo@kemri-wellcome.org

Received 27 June 2014 Revised 30 September 2014 Accepted 28 October 2014 Published Online First 8 December 2014
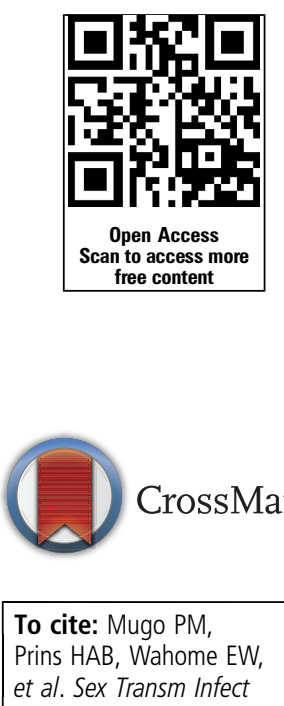

\begin{abstract}
Background Adults in developing countries frequently use community pharmacies as the first and often only source of care. The objective of this study was to assess the success of pharmacy referrals and uptake of HIV testing by young adult clients of community pharmacies in the context of a screening programme for acute HIV-1 infection (AHI).

Methods We requested five pharmacies to refer clients meeting predefined criteria (ie, 18-29 years of age and requesting treatment for fever, diarrhoea, sexually transmitted infection (STI) symptoms or body pains) for HIV-1 testing and AHI screening at selected clinics. Using multivariable logistical regression, we determined client characteristics associated with HIV-1 test uptake.

Results From February through July 2013, 1490 pharmacy clients met targeting criteria (range of weekly averages across pharmacies: 4-35). Of these, 1074 (72\%) accepted a referral coupon, $377(25 \%)$ reported at a study clinic, 353 (24\%) were HIV-1 tested and 127 (9\%) met criteria for the AHI study. Of those tested, 14 (4.0\%) were HIV-1 infected. Test uptake varied significantly by referring pharmacy and was higher for clients who presented at the pharmacy without a prescription versus those with a prescription, and for clients who sought care for STI symptoms.

Conclusions About a quarter of targeted pharmacy clients took up HIV-1 testing. Clients seeking care directly at the pharmacy (ie, without a prescription) and those with STI symptoms were more likely to take up HIV-1 testing. Engagement of adult pharmacy clients for HIV-1 screening may identify undiagnosed individuals and offers opportunities for HIV-1 prevention research.
\end{abstract}

\section{INTRODUCTION}

Adults in developing countries frequently use community pharmacies as the first and often only source of care, owing to greater accessibility, lower cost or greater perceived privacy. ${ }^{1} 2$ The factors driving direct care seeking at pharmacies may not be easily modifiable, yet pharmacy clients have not been included in provider-initiated testing and counselling programmes $^{34}$ or targeted in community-based strategies. $^{5}$ In an assessment of treatment practices, we found that only $10 \%$ pharmacies would recommend HIV-1 testing to a client with urethritis. ${ }^{6}$

We have recently reported results of an acute HIV infection (AHI) screening study based in clinics, with referral of potentially eligible participants from pharmacies. ${ }^{7}$ The objective for the present study was to evaluate the success of pharmacy referrals and uptake of HIV testing by pharmacy clients in the context of this AHI screening programme.

\section{METHODS}

\section{Selection and training of pharmacies}

The study was conducted in Mtwapa area of Coastal Kenya. Out of 20 pharmacies included in a previous survey, ${ }^{6}$ we selected five that had reported high client loads in the survey and were willing to refer clients for research. We trained pharmacy staff on client engagement and referral through frequent on-site visits (at least weekly) and occasional off-site sessions (beginning of the study and at least monthly). Pharmacies provided input to the design of study materials, including a leaflet of key messages and a referral coupon.

\section{Client referral procedure}

Pharmacy workers were requested to target all clients aged 18-29 years purchasing medicine for fever, sexually transmitted infection (STI) symptoms, diarrhoea or body pains. These clients were referred using a numbered coupon to any of five participating clinics for free HIV-1 testing and screening for the AHI study. Other testing and follow-up procedures are detailed elsewhere. ${ }^{7}$ Client engagement was supported by three community volunteers. Pharmacy staff received Ksh 125 (US\$1 $\approx$ KSh 85 ) when a client presented at a study clinic and an additional Ksh 75 if the client was enrolled in the AHI study.

\section{Data collection and analysis}

Data collected at the pharmacy included age, sex, whether client had a prescription, area of residence, symptom for which treatment was sought (recording multiple symptoms when reported), referring pharmacy, staff initials and referral date. Characteristics captured were of the presenting client, unless the client self-identified as a surrogate client (eg, partner), in which case details of the actual patient were captured. We compared the sex variable across pharmacy and clinical data, as a rough measure to assess whether the coupon changed hands. 
Factors associated with test uptake (number tested/number targeted) were examined by univariable and multivariable logistical regression. A sensitivity analysis was conducted to evaluate factors associated with test uptake among the subset of pharmacy clients who accepted the referral coupon. All variables with $\mathrm{p}<0.10$ from univariable modelling were included in multivariable modelling. A two-sided $\mathrm{p}$ value $<0.05$ indicated statistical significance. All analyses were performed using Stata (StataCorp, College Station, Texas, USA).

\section{RESULTS}

From February through July 2013, 1490 clients met AHI targeting criteria (range of weekly averages across pharmacies: 4-35). Of these, 1074 (72.1\%) accepted a referral coupon, 377 (25\%) reported for screening at study clinics, 353 (24\%) were HIV-1 tested (21 were unwilling to test and three were known HIV positive) and 127 (9\%) met criteria for the AHI study. Of those tested, $43(13 \%)$ had never tested before, 52 (15\%) had not tested in the last year and 14 (4.0\%) were HIV-1 infected.

Test uptake varied significantly by referring pharmacy and was higher for clients who presented at the pharmacy without a prescription versus those with a prescription (table 1). Seeking treatment for STI symptoms was marginally associated with higher test uptake, while body pains were associated with lower test uptake. Among the subset of clients accepting the referral coupon, test uptake was higher for those without a prescription (aOR 2.3, 95\% CI 1.5 to $3.6, \mathrm{p}<0.001$ ) and those with STI symptoms (aOR 1.3, 95\% CI 1.0 to 2.0, $\mathrm{p}=0.03)$.

The odds of an HIV diagnosis was higher among clients aged 25-29 years than those aged 18-24 years (aOR 10.5, 95\% CI 1.3 to $82.2, p=0.03$ ), but did not vary by pharmacy, sex, residence, prescription or treatment sought.

\section{DISCUSSION}

To our knowledge, this is the first study in a developing country setting to target community pharmacy clients for HIV-1 testing and engagement in prevention research. Over $70 \%$ of targeted clients accepted the referral coupon; a quarter took the test and over a quarter of those tested had not tested in the last year. Clients seeking care directly at the pharmacy (ie, without a

Table 1 Characteristics of adult pharmacy clients referred and tested for HIV-1 in Coastal Kenya, 2013

\begin{tabular}{|c|c|c|c|c|c|c|}
\hline \multirow[b]{2}{*}{ Characteristic } & \multirow[b]{2}{*}{ Targeted, n } & \multirow[b]{2}{*}{ Tested $\mathbf{n}$ ( $\%$ of targeted) } & \multicolumn{2}{|c|}{ Univariable analysis } & \multicolumn{2}{|c|}{ Multivariable analysis** } \\
\hline & & & OR $(95 \% \mathrm{Cl})$ & $\mathrm{p}$ Value & OR $(95 \% \mathrm{Cl})$ & $\mathrm{p}$ Value \\
\hline Total number of clients & 1490 & $353(24 \%)$ & $\mathrm{n} / \mathrm{a}$ & $\mathrm{n} / \mathrm{a}$ & & \\
\hline \multicolumn{7}{|l|}{ Referring pharmacy } \\
\hline Pharmacy 1 & 262 & $22(8 \%)$ & Ref & Ref & Ref & Ref \\
\hline Pharmacy 2 & 96 & $16(17 \%)$ & 2.2 (1.1 to 4.4$)$ & 0.03 & 2.2 (1.1 to 4.4$)$ & 0.03 \\
\hline Pharmacy 3 & 380 & $74(19 \%)$ & $2.6(1.5$ to 4.4$)$ & $<0.001$ & 1.9 (1.1 to 3.2$)$ & 0.02 \\
\hline Pharmacy 4 & 60 & $12(20 \%)$ & 2.7 (1.3 to 5.9$)$ & 0.01 & 2.1 (1.0 to 4.6$)$ & 0.06 \\
\hline Pharmacy 5 & 692 & $229(33 \%)$ & 5.3 (3.4 to 8.6$)$ & $<0.001$ & 5.0 (3.1 to 8.1$)$ & $<0.001$ \\
\hline \multicolumn{7}{|l|}{ Age, years } \\
\hline $18-24$ & 681 & $150(22 \%)$ & Ref & Ref & - & - \\
\hline $25-29$ & 809 & $203(25 \%)$ & $1.2(0.9$ to 1.5$)$ & 0.2 & - & - \\
\hline \multicolumn{7}{|c|}{ Sex of person presenting at pharmacy* } \\
\hline Female & 706 & $168(24 \%)$ & Ref & Ref & - & - \\
\hline Male & 760 & $184(24 \%)$ & $1.0(0.8$ to 1.3$)$ & 0.9 & - & - \\
\hline \multicolumn{7}{|l|}{ Area of residencet } \\
\hline Shanzu & 145 & 27 (19\%) & Ref & Ref & - & - \\
\hline Mtwapa & 1333 & $316(24 \%)$ & $1.4(0.9$ to 2.1$)$ & 0.2 & - & - \\
\hline \multicolumn{7}{|l|}{ Prescription presented $\ddagger$} \\
\hline Yes & 361 & $29(8 \%)$ & Ref & Ref & Ref & Ref \\
\hline No & 1109 & $318(29 \%)$ & $4.6(3.1$ to 6.9$)$ & $<0.001$ & 5.0 (3.3 to 7.7$)$ & $<0.001$ \\
\hline \multicolumn{7}{|l|}{ Treatment sought§ } \\
\hline \multicolumn{7}{|l|}{ Fever } \\
\hline No & 748 & $178(24 \%)$ & Ref & Ref & - & - \\
\hline Yes & 742 & $175(24 \%)$ & $1.0(0.8$ to 1.3$)$ & 0.9 & - & - \\
\hline \multicolumn{7}{|l|}{ Diarrhoea } \\
\hline No & 1288 & $309(24 \%)$ & Ref & Ref & - & - \\
\hline Yes & 202 & $44(22 \%)$ & $0.9(0.6$ to 1.3$)$ & 0.5 & - & - \\
\hline \multicolumn{7}{|l|}{ STI symptoms } \\
\hline No & 1135 & $237(21 \%)$ & Ref & Ref & Ref & Ref \\
\hline Yes & 355 & $116(33 \%)$ & 1.8 (1.4 to 2.4$)$ & $<0.001$ & 1.3 (1.0 to 1.8$)$ & 0.08 \\
\hline \multicolumn{7}{|l|}{ Body pains } \\
\hline No & 953 & $256(27 \%)$ & Ref & Ref & Ref & Ref \\
\hline Yes & 537 & $97(18 \%)$ & $0.5(0.7$ to 0.8$)$ & $<0.001$ & 0.5 (0.3 to 0.6$)$ & $<0.001$ \\
\hline
\end{tabular}

*Sex was missing for 24 clients. For 96 referrals, the sex of the person presenting at the study clinic was different from that of the person initially referred, mainly due to sharing of referral coupons.

**Variables included in the multivariable analysis were: referring pharmacy, prescription presented (yes/no), STI symptoms (yes/no) and body pains (yes/no).

†Area of residence was missing for 12 clients. Prescription was missing for 20 clients. $\S A$ total of $339(22.7 \%)$ clients sought treatment for more than one symptom, including 333 with two symptoms and six with three symptoms. Antimalarial medications were counted as treatment for fever. 
prescription) and those with STI symptoms were more likely to take up testing.

Our findings demonstrate that pharmacy clients can be engaged for HIV-1 testing and prevention research. However, further research is needed to identify factors associated with HIV test uptake at pharmacies in non-research settings. Results of this pilot study suggest that referral uptake could be boosted through improved communication skills among pharmacy workers and by focusing on patients with STI symptoms.

Alternatives to referral also need to be explored. We documented demand for HIV testing kits at some of the participating pharmacies, although anecdotally. Previous studies have found self-testing to be feasible and effective in community settings, ${ }^{8}$ and Kenyan National Guidelines recognise the role of the community pharmacies as a reliable source of self-testing kits. ${ }^{9}$ A self-testing intervention should be developed, targeting clients most at-risk for undiagnosed prevalent HIV-1 (eg, patients presenting with STI symptoms or fever). Such an intervention could increase awareness of HIV status and uptake of recommended retesting among Kenyan adults. ${ }^{9}$ Testing could also be done within the pharmacy premises for patients who are illiterate or uncomfortable testing themselves. The feasibility of such an approach has been proven in the $\mathrm{USA}^{10}$ and should be explored in our setting.

This study has limitations, including selection of pharmacies with documented high numbers of clients, a narrow age group (ie, young adults aged 18-29 years), a short study period; possible sharing of coupons, and the research context of this assessment, since patients being screened for the AHI study as well as pharmacy staff received financial incentives.

In conclusion, we found that engagement of adult pharmacy clients for HIV-1 testing may identify undiagnosed individuals and may offer opportunities for prevention research. Clients seeking care directly at the pharmacy without a prescription and those with STI symptoms were more likely to take up HIV-1 testing. Operational research is required to identify ways to improve HIV test access and uptake among pharmacy clients.

\section{Key messages}

- Targeting community pharmacy clients for HIV-1 testing resulted in detection of undiagnosed infections and enhanced knowledge of HIV status.

- Engagement of pharmacy clients in HIV-1 prevention research is feasible.

- HIV-1 testing at pharmacy premises or provision of selftesting services through pharmacies may increase HIV testing and diagnosis, and should be assessed in developing country settings.

Acknowledgements We would like to acknowledge the contributions of the study clients to this research. We thank Jennifer Kanungi, Ruth Nganga, Esther Ndiang'ui,
John Mwambi and Caroline Ngetsa, of the KEMRI-Wellcome Trust Research Programme, for quality control data entry, and laboratory support. We also thank Maureen Nyandzua, Elizabeth Njogu and Anisa Furaha for supporting client engagement and data collection. Special thanks go to key personnel at study pharmacies: Nicholas Katumo (New Vipingo), Everlyne Masese (New Mtwapa), Fred Maina (North Coast), Rachel Nzau (Southcoast) and Peter Oyaro (Pesphiel).

\section{Handling editor Jackie A Cassell}

Contributors Designed the study: PMM and EJS; supported community engagement: $E G$ and $A O$; trained pharmacies and collected the data: PMM, HABP, EWW, GMM and ANT; analysed the data: PMM, EJS, EWW and SMG. Wrote the paper: PMM, EJS, SMG, HABP, EWW, GMM, ANT, EG and AO.

Funding We thank the International AIDS Vaccine Initiative (IAVI) for funding this study. IAVI's work is made possible by generous support from many donors, http:/l www.iavi.org. The KWTRP at the Centre for Geographical Medicine Research-Kilifi is supported by core funding from the Wellcome Trust (\#077092). SMG was supported by NIH grant 1R34MH099946-01 and the University of Washington Center for AIDS Research (CFAR). This study is made possible by the generous support of the American people through the United States Agency for International Development (USAID). The contents are the responsibility of the study authors and do not necessarily reflect the views of USAID, the NIH or the US Government. This report was published with permission from KEMRI.

\section{Competing interests None.}

Ethics approval The study was approved by the ethical review committees at the Kenya Medical Research Institute (SSC2359), and the University of Oxford (167-12). Clients presenting at study clinics received Ksh 100 for transport.

Provenance and peer review Not commissioned; externally peer reviewed.

Open Access This is an Open Access article distributed in accordance with the terms of the Creative Commons Attribution (CC BY 4.0) license, which permits others to distribute, remix, adapt and build upon this work, for commercial use, provided the original work is properly cited. See: http://creativecommons.org/ licenses/by/4.0/

\section{REFERENCES}

1 Fonck K, Mwai C, Rakwar J, et al. Healthcare-seeking behavior and sexual behavior of patients with sexually transmitted diseases in Nairobi, Kenya. Sex Transm Dis 2001;28:367-71

2 Onwujekwe 0, Hanson K, Uzochukwu B. Do poor people use poor quality providers? Evidence from the treatment of presumptive malaria in Nigeria. Trop Med Int Health 2011;16:1087-98.

3 Roura M, Watson-Jones D, Kahawita TM, et al. Provider-initiated testing and counselling programmes in sub-Saharan Africa: a systematic review of their operational implementation. AIDS 2013;27:617-26.

4 Ministry of Health; National AIDS and STI Control Program (NASCOP): Guidelines on Use of Antiretroviral Drugs for Treating and Preventing HIV Infection: A rapid advice. 2014; Accessed.

5 Suthar AB, Ford N, Bachanas PJ, et al. Towards universal voluntary HIV testing and counselling: a systematic review and meta-analysis of community-based approaches. PLoS Med 2013;10:e1001496.

6 Mugo PM, Duncan S, Mwaniki SW, et al. Cross-sectional survey of treatment practices for urethritis at pharmacies, private clinics and government health facilities in coastal Kenya: many missed opportunities for HIV prevention. Sex Transm Infect 2013;89:583-9

7 Sanders EJ, Mugo P, Prins HA, et al. Acute HIV-1 infection is as common as malaria in young febrile adults seeking care in coastal Kenya. AIDS 2014;28:1357-63.

8 Pant Pai N, Sharma J, Shivkumar S, et al. Supervised and unsupervised self-testing for HIV in high- and low-risk populations: a systematic review. PLoS Med 2013;10: e1001414.

9 Kenya Ministry of Health, National Aids and STI Control Programme: National Guidelines for HIV Testing and Counselling in Kenya. 2010. http://nascop.or.ke/ library/HTC/National\%20Guidelines\%20for\%20HTC\%20in\%20Kenya\%202010.pdf (accessed 3 Sep 2012)

10 Calderon Y, Cowan E, Rhee JY, et al. Counselor-based rapid HIV testing in community pharmacies. AIDS Patient Care STDS 2013;27:467-73. 